\title{
AGRICULTURAL BIOTECHNOLOGY
}

\section{Modifying bacterial symbionts for biocontrol \\ Nat. Biotechnol. https://doi.org/10.1038/s41587-020-0419-1 (2020)}

Plant pests and pathogens threaten global food security. Biological control involves the use of natural enemies to reduce the pest populations. It is cost-effective with minimized negative environmental consequences. However, the efficacy of biocontrol agents can be limited for some pests, such as the western corn rootworm (WCR, Diabrotica virgifera virgifera). Now researchers suggest that modification of bacterial symbionts to enhance the performance of their host might represent a strategy to improve the biocontrol potential of WCR.

WCR is among the most damaging maize pests, causing over US $\$ 2$ billion worth of damage every year. Previous studies show that the WCR larvae accumulate the maize root-derived benzoxazinoid glucosides, and produce toxic products that can reduce the survival of both the biological control agent - entomopathogenic nematodes (EPNs) and its Photorhabdus bacterial symbionts. Through directed evolution, Ricardo A. R. Machado of the University of Bern and colleagues increased the benzoxazinoid resistance of the Photorhabdus bacterial symbionts. They re-introduced benzoxazinoid-resistant strains into the original EPN hosts and identified one nematode-symbiont pair that was able to kill WCR larvae more efficiently.

Using WCR as an example, this work could help efforts to develop more effective biocontrol methods in staple food crops such as maize, and adds knowledge of biocontrol for sustainable food production towards the food system target for 2050.

Yufang Guo

Published online: 17 March 2020

https://doi.org/10.1038/s43016-020-0056-3 